\title{
Familial benign copper deficiency
}

INSERM

\section{Source}

INSERM. (1999). Orphanet: an online rare disease and orphan drug data base. Familial benign copper deficiency. ORPHA:1551

Familial benign copper deficiency is a rare disorder of mineral absorption and transport characterized by hypocupremia that manifests as failure to thrive, mild anemia, repeated seizures, hypotonia, and seborrheic skin. Spurring of the femur and tibia are also noted on radiog raphic imaging. Symptoms are reversible or improve with supplements of oral copper. There have been no further descriptions in the literature since 1988. 